\title{
Effect of Volleyball Training Program to Improve Reaction Time
}

\author{
Sri Mawarti ${ }^{1, *}$, Nur Azis Rohmansyah ${ }^{2}$, Ashira Hiruntrakul ${ }^{3}$ \\ ${ }^{1}$ Department of Physical Education, Universitas Negeri Yogyakarta, Yogyakarta, Indonesia \\ ${ }^{2}$ Department of Physical Education, Unversitas PGRI Semarang, Semarang, Indonesia \\ ${ }^{3}$ Department of Sport and Exercise Sciences, Nong Khai Campus, Khon Kaen University, Nong Khai, Thailand
}

Received August 26, 2021; Revised October 11, 2021; Accepted October 28, 2021

\section{Cite This Paper in the following Citation Styles}

(a): [1] Sri Mawarti, Nur Azis Rohmansyah, Ashira Hiruntrakul, "Effect of Volleyball Training Program to Improve Reaction Time," International Journal of Human Movement and Sports Sciences, Vol. 9, No. 6, pp. 1314 - 1318, 2021. DOI: $10.13189 /$ saj.2021.090627.

(b): Sri Mawarti, Nur Azis Rohmansyah, Ashira Hiruntrakul (2021). Effect of Volleyball Training Program to Improve Reaction Time. International Journal of Human Movement and Sports Sciences, 9(6), 1314 - 1318. DOI: 10.13189/saj.2021.090627.

Copyright $(2021$ by authors, all rights reserved. Authors agree that this article remains permanently open access under the terms of the Creative Commons Attribution License 4.0 International License

\begin{abstract}
This study aims to analyze the difference in the effect of the side shuffle drill and shuffle reaction ball drill training methods on the reaction speed of volleyball athletes. The study is a $2 \times 2$ factorial blinded randomized controlled trial. This study was divided into 4 treatment groups, each group ( 9 athletes) is trained by a trainer who has the same qualifications and in the implementation of the training program 3 times a week training for 18 times with a span of 120 minutes using side shuffle drill and shuffle reaction ball drill and supervised by a trainer coordinator. Trainers who carry out the training program are drawn at random so that all have the opportunity to train one of the four groups. The results showed that there was a significant difference in the effect of side shuffle drill and shuffle reaction ball drill exercises on the reaction rate of volleyball athletes. The shuffle reaction ball drill method has been proven to have a significant effect on increasing the reaction speed of volleyball youth athletes.
\end{abstract}

Keywords Side Shuffle Drill, Ball Drill Shuffle Reaction, Agility, Reaction Speed, Volleyball

\section{Introduction}

Volleyball is a team game and there must be a good understanding and coordination among players to be effective as a group. Motor components are concerned.
Volleyball requires agility, coordination and reaction ability for playing and a good suspicion to lift and hit the ball. In volleyball, changes in the speed of game and scoring system the set finishes quickly, so players need a high level of agility, coordination and reaction ability [1], [2].

One of the physical abilities is reaction, which is the ability of a person to act quickly in response to a stimulus that comes from outside either through the senses of nerves or feelings [3], [4]. Movement speed is the most important ability in achievement sports because the majority of athletes are required to run, move, react, or change direction quickly.

Basically, in playing volleyball, to score a point or generate points quickly, it must improve agility, coordination and reaction skills [1], [2]. One of the physical abilities is reaction, which is the ability of a person to act quickly in response to a stimulus that comes from outside either through the senses of nerves or feelings [3], [5]. Movement speed is the most important ability in achievement sports because the majority of athletes are required to run, move, react, or change direction quickly.

The speed of moving or reacting and agility are needed in sports, especially in volleyball which of course must move agile in mastering the corner of the field and react quickly to the ball that comes. There are still many models or variations of exercise to improve the reaction of an athlete, of course the existing training is adjusted to the 
needs of the sport. Exercises that lead to fast-moving reaction speed are side shuffle drill and shuffle reaction ball drill. These exercises were developed by [3], [5], [6]. Side shuffle drill exercise is an exercise that is useful for increasing response to stimuli using visual stimuli and step speed in athletes who are lacking in reaction speed [3], [5], [6]. The Side Shuffle is a popular agility exercise used among athletes of all fitness levels. It is considered an agility exercise that helps with coordination, agility, balance and speed. [3], [5], [6] expressed their opinion to do this exercise from a standing position with feet hip-width apart, feet shoulder-width apart and body down to a half-squat position. While maintaining a semi-squat position, move by taking shoulder-width steps according to the intrusion directed by the trainer, side shuffle can help athletes move actively and spin quickly on the court. This required Directional Shift greatly improves the athlete's performance during the match. It also allows quickly regaining balance after an unexpected move. Athletes will move instantly and reactively refers to a fast response. Doing side shuffle exercises has many benefits, for example, improve balance, agility, coordination, speed and response time.

Shuffle reaction ball drill exercise improves reaction time and dexterity skills by using a stimulus about the sense of response to sight [3], [5], [6]. Shuffle reaction ball drill is an exercise to increase the time for react and dexterity skills by using a stimulus about the sense of response to seeing [3], [5], [6]. This drill is performed instead of tossing a ball to the athlete, the coach or partner rolls volleyballs on the ground to the cones on the left and right of the athlete. This forces the player to stay in a low position while moving laterally. The coach or partner can vary when he releases the ball to change up the movement pattern and reaction time. The athlete will go for a set period of time.

Agility is an important component needed by almost all sports, which is the ability to change the direction or position of the body quickly which is done together with other movements. An athlete who has good agility will be able to perform movements more effectively and efficiently. Agility is defined as the physical ability of an individual to rapidly change the body position and direction in a precise manner. In the game of volleyball, players have to cover different distances in different directions to perform dive, roll and fall to receive the ball frequently. During the attack hit [defensive block], the ball may change its movement in an uncertain direction and go far away from the player in a different trajectory. Agility is highly dependent on coordination and movement control but apart from coordination there is a substantial number of factors that affect the level of agility such as mobility of joints, dynamic balance, power and flexibility, level of energy resources, strength, speed and optimal biomechanical structures of movement. Agility is recognized as the ability to maintain and control the position of the body while rapidly moving and changing directions as a response to a stimulus. It seems to be related to athletic abilities like strength, power, speed and balance and it's a determinant of sport performance in field and court sports like volleyball, soccer and rugby.

Thus, this study aims to analyze the difference in the effect of the side shuffle drill and shuffle reaction ball drill training methods on the reaction speed of volleyball athletes.

\section{Method}

The study is a $2 \times 2$ factorial blinded randomized controlled trial. This study was divided into 4 treatment groups, a group of volleyball athletes who have high agility are trained by the side shuffle drill method (A1B1), a group of volleyball athletes who have low agility are trained by the side shuffle drill method (A1B2), a group of volleyball athletes who have high agility are trained with the shuffle reaction ball drill training method (A2B1), and a groups of volleyball athletes who have low agility are trained with the shuffle reaction ball drill training method (A2B2).

Each group (9 athletes) trained by a trainer who has the same qualifications and in the implementation of the training program 3 times a week training for 18 times with a span of 120 minutes using side shuffle drill and shuffle reaction ball drill and supervised by a trainer coordinator. Trainers who carry out the training program are drawn at random so that all have the opportunity to train one of the four groups.

The division of the experimental group is based on the initial ability of the agility test. Agility in this study is indicated by the agility value measured using the hexagonal obstacle test with a validity of (0.99) and a reliability of (0.94). After the initial test results were ranked, subjects with equal abilities were paired into group 1 and group 2. Thus, the two groups before being given treatment had become a balanced group. Furthermore, the sampling technique used in this study is $t$ simple random sampling. Reaction speed was carried out using the Whole Body Reaction Time Test with reliability coefficients $(0.93)$ and validity $(0.607)$.

\subsection{Statistical Analysis}

Calculation of data normality in this study using Kolmogorov Smirnov $(\alpha>0.05)$ and homogeneity test was carried out using the Levene test formula $(\alpha<0.05)$. Hypothesis testing uses two-way ANOVA multivariant test with the help of SPSS version 20.0.

\section{Results}

There was a significant difference in the effect of the 
side shuffle drill and shuffle reaction ball drill methods on the reaction speed of adolescent volleyball athletes $(p=0.001)$ (table 1$)$. There is a significant difference in the reaction speed of volleyball youth athletes who have high agility and low agility $(\mathrm{p}=0.007)$ (table 2$)$. There was a significant interaction between side shuffle drill and shuffle reaction ball drill and agility to increase the reaction speed of volleyball youth athletes $(p=0.001)$ (table 3). The different groups that showed a significant difference were A1B1-A2B1, A2B1-A1B2, A2B1-A2B2, while the groups that did not have a different effect were A1B1-A1B2, A1B1-A2B2, A1B2-A2B2 (table 4).

\section{Discussion}

This study shows that there is a significant difference in the effect of side shuffle drill exercises and shuffle reaction ball drill exercises on the reaction speed of volleyball athletes. The shuffle reaction ball drill with a higher score showed a significant difference compared to the side shuffle drill. Shuffle reaction ball drill is an exercise to increase reaction time and dexterity skills by using a stimulus about the sense of response to seeing [5-9].

Shuffle reaction ball drill exercises as a whole can train movements to be more skilled, agile and increase the time to react to stimuli received by the senses [10]. This makes athletes better at making movements quickly and appropriately responding to existing stimuli.

Table 1. Training Method on the reaction speed of volleyball athletes

\begin{tabular}{cccccc}
\hline Source & Type III Sum of Squares & df & Mean Square & F & p \\
\hline $\begin{array}{c}\text { Side Shuffle Drill and } \\
\text { Shuffle Reaction Ball Drill }\end{array}$ & 0.001 & 1 & 0.001 & 41.846 & 0.001 \\
\hline
\end{tabular}

Table 2. The difference in reaction speed of volleyball athletes with agility with high and low scores

\begin{tabular}{cccccc}
\hline Source & Type III Sum of Squares & df & Mean Square & F & p \\
\hline Agility & $4.778 \mathrm{E}-6$ & 1 & $4.778 \mathrm{E}-6$ & 8.230 & 0.007 \\
\hline
\end{tabular}

Table 3. Side Shuffle Drill and Shuffle Reaction Ball Drill and agility with increased reaction speed

\begin{tabular}{cccccc}
\hline Source & Type III Sum of Squares & df & Mean Square & F & p \\
\hline $\begin{array}{c}\text { Side Shuffle Drill and Shuffle Reaction } \\
\text { Ball Drill with agility }\end{array}$ & 0.001 & 1 & 0.001 & 40.240 & 0.001 \\
\hline
\end{tabular}

Table 4. Groups that have significantly different interactions or partners

\begin{tabular}{|c|c|c|c|c|}
\hline Group & Interaction & Mean Difference & SE & $\mathbf{p}$ \\
\hline \multirow[t]{3}{*}{ A1B1 } & A1B2 & -.00248 & 0.001219 & 0.098 \\
\hline & $\mathrm{A} 2 \mathrm{~B} 1$ & $-.01011^{*}$ & 0.001219 & 0.001 \\
\hline & $\mathrm{A} 2 \mathrm{~B} 2$ & -.00279 & 0.001219 & 0.079 \\
\hline \multirow[t]{3}{*}{ A1B2 } & A1B1 & 0.00269 & 0.001219 & 0.098 \\
\hline & $\mathrm{A} 2 \mathrm{~B} 1$ & $-.00855^{*}$ & 0.001219 & 0.001 \\
\hline & $\mathrm{A} 2 \mathrm{~B} 2$ & -.00023 & 0.001219 & 1.001 \\
\hline \multirow[t]{3}{*}{ A2B1 } & A1B1 & $0.01031^{*}$ & 0.001219 & 0.001 \\
\hline & A1B2 & $0.00823^{*}$ & 0.001219 & 0.001 \\
\hline & A2B2 & $0.00745^{*}$ & 0.001219 & 0.001 \\
\hline \multirow[t]{3}{*}{ A2B2 } & A1B1 & 0.00398 & 0.001219 & 0.068 \\
\hline & $\mathrm{A} 2 \mathrm{~B} 1$ & $-.00822 *$ & 0.001219 & 0.001 \\
\hline & $\mathrm{A} 2 \mathrm{~B} 2$ & 0.00012 & 0.001219 & 1.001 \\
\hline
\end{tabular}

*The different groups that showed a significant difference were A1B1-A2B1, A2B1-A1B2, A2B1-A2B2, while between groups that did not have a different effect were A1B1-A1B2, A1B1-A2B2, A1B2-A2B2 
Based on the results of the study, it can be concluded that the shuffle reaction ball drill exercise increases the reaction speed in volleyball because the ball drill shuffle reaction has the aim of increasing the time to react and agility skills when responding to the stimuli received. React quickly when getting a stimulus or stimulus from outside. This quick reaction in the form of moving quickly tries to reach and catch a ball that is thrown from side to side randomly. In a volleyball game, this movement can be seen as an example when defending, resisting or covering, trying to receive, reach and defend the ball so that it does not fall to the ground so that it can pass and form an attack.

The shuffle reaction ball drill is better at improving reaction ability because the shuffle reaction ball drill exercise will make the athlete more motivated to move in all sides or directions in response to the existing stimuli. With the stimulus in the form of a ball being thrown to all sides at random, the athlete will be motivated to react to the stimulus by trying to catch, reaching the ball so it doesn't fall to the ground, meaning saved.

Side shuffle exercise is an exercise that is useful for increasing response to stimuli by using visual stimuli and step speed for athletes who are lacking in reaction [8], [11]. Side shuffle can help athletes move actively and spin quickly on the court. This required directional shift greatly improves the athlete's performance during the match. It also allows quickly regaining balance after an unexpected move. Athletes will move instantly and reactively refers to a fast response. Doing the side shuffle exercise has many benefits for increasing speed and response.

There is a significant difference in the reaction speed of volleyball athletes who have high agility and low agility. Based on the results of the analysis, it turns out that players with high agility will be better than players with low agility. Agility is one of the biomotor components that is indispensable in all activities that require the speed of changing the position of the body and its parts [3], [5], [12]. Agility is very important for sports that require high adaptability to changing situations in the match. However, [7] argues that agility is the ability to change the direction or position of the body quickly which is done together with other movements.

Research conducted by [4], [10], [13] that motor fitness components such as agility, speed, reaction and others will support skills in volleyball games. It can be seen from the results showing the magnitude of the correlation between the value of motor fitness with volleyball skills.

Other research results by [2], [3], [5] stated that agility has a direct effect on over-passing skills. This confirms that agility has a direct effect on volleyball passing skills. As a volleyball player, you must have an element of agility, and this special agility can be obtained with serious training results, and without agility the players cannot play well and will not develop especially for achievement purposes.
Reaction speed is a person's ability to respond to stimuli in the shortest possible time, and reaction time is a critical success factor in almost all sports [5], [14], [15]. One of them in volleyball requires a good physical background, mobility, jumping ability, quick reaction, ground orientation and coordination.

With this in mind, coaches must develop programs that will improve the player's ability to react and move in any direction. Reaction in any sport is the beginning of speed. Athletes must learn how to recognize and interpret what is happening around them, and then react well to stimuli so that they can perform the correct skills required for the game situation.

There is a significant interaction between training methods (side shuffle drill and shuffle reaction ball drill) and agility (high and low) to increase the reaction speed of volleyball youth athletes. The results showed that the shuffle reaction ball drill method was the most effective method used for players with high agility and the side shuffle drill method was more effective for players with low agility.

\section{Conclusions}

The application of side shuffle drill and shuffle reaction ball drill exercises has a significant difference in increasing the reaction speed of volleyball youth athletes. This indicates that in reaction speed training, the application of the shuffle reaction ball drill method is more appropriate to increase the reaction speed of volleyball athletes. The shuffle reaction ball drill method has been proven to have a significant effect on increasing the reaction speed of volleyball youth athletes.

The limitations of the study during exercise or application of treatment were that all groups were not collected or quarantined, so that there was no control over what activities the sample did outside of exercise, but rather stayed in their respective homes. This can affect the results of the study indirectly. Lack of control over other elements outside of training can affect the training process.

\section{REFERENCES}

[1] Freire A, Benda R, Costa G, Figueiredo L, Mitre G, Matos C, et al., "Validity and reliability of observational scales for volleyball techniques: Floating serve with support, block and defense," Revista Andaluza de Medicina del Deporte, vol. 12 , no. 1 , pp. 7-10, 2019. DOI: 10.33155/j.ramd.2018. 06.002 .

[2] Risma Sa, Dlis F, Samsudin S., "Variation of Volleyball Basic Technique Through Games Approach," Journal of Physical Education Sport Health and Recreation, vol. 9, no. 2, pp. 131-136, 2020. DOI: 10.15294/active.v9i2.39056. 
[3] Lima R, Rico-González M, Pereira J, Caleiro F, Clemente F., "Reliability of a reactive agility test for youth volleyball players. Polish Journal of Sport and Tourism," vol. 28, no. 1, pp. 8-12, 2021. DOI: 10.2478/pjst-2021-0002.

[4] Trecroci A, Duca M, Cavaggioni L, Rossi A, Scurati R, Longo S, et al., "Relationship between cognitive functions and sport-specific physical performance in youth volleyball players," Brain Sciences, vol. 11, pp. 227, 2021. DOI: 10.3390/brainsci11020227.

[5] Šimonek J, Horička P, Hianik J., "Differences in pre-planned agility and reactive agility performance in sport games," Acta Gymnica, vol. 46, no. 2, pp. 68-73, 2016. DOI: 10.5507/ag.2016.006.

[6] Choksi T, Anandh S., "Effectiveness of tailored reaction time training drills in addition to warm-up sessions on performance parameters in recreational cricket players," Indian Journal of Forensic Medicine and Toxicology, vol. 14, no. 3, pp. 6, 2020. DOI: 10.37506/ijfmt.v14i3.10758.

[7] Rusdiana A., "Development of agility, coordination, and reaction time training device with infrared sensor and wifi module arduino in badminton," Songklanakarin Journal of Sciences Technology, vol. 43, no. 2, pp. 448-452, 2021. DOI: $10.14456 /$ sjst-psu. 2021.58

[8] Hülsdünker T, Gunasekara N, Mierau A., "Short- and Long-Term Stroboscopic Training Effects on Visuomotor Performance in Elite Youth Sports. Part 1: Reaction and Behavior," Medicine and Sciences Sports and Exercise, vol. 53, no. 5, pp. 960-972, 2021. DOI: 10.1249/MSS.0000000000002541.

[9] Pruna Gj, Hoffman Jr, Mccormack Wp, Jajtner Ar, Townsend Jr, Bohner Jd, et al., "Effect of acute L-Alanyl-L-Glutamine and electrolyte ingestion on cognitive function and reaction time following endurance exercise," European Journal of Sport Sciences, vol. 16, no.
1, pp. 72-79, 2016. DOI: 10.1080/17461391.2014.969325.

[10] Obour A, Moses Mo, Baffour-Awuah B, Asamoah B, Sarpong Pk, Osei F, et al., "Differences in Physical, Physiological and Motor Performance Traits between Volleyball and Basketball Athletes in a University in Ghana," Nigerian Journal of Physiological Sciences, vol. 32, no. 1, pp. 27-31, 2017.

[11] Trajković N, Sporiš G, Krističević T, Madić Dm, Bogataj Š., "The importance of reactive agility tests in differentiating adolescent soccer players," International Journal of Environmental Research and Public Health, vol 17, pp. 3839, 2020. DOI: 10.3390/ijerph17113839.

[12] Falcone Ph, Tribby Ac, Vogel Rm, Joy Jm, Moon Jr, Slayton Ca, et al., "Efficacy of a nootropic spearmint extract on reactive agility: A randomized, double-blind, placebo-controlled, parallel trial," Journal of the International Society of Sports Nutrition, vol 15, no. 1, pp. 58, 2018. DOI: 10.1186/s12970-018-0264-5.

[13] Wilkerson Gb, Nabhan Dc, Crane Rt., "Upper-Extremity Perceptual-Motor Training Improves Whole-Body Reactive Agility Among Elite Athletes With History of Sport-Related Concussion," Journal of Sport Rehabilitation, vol. 8, pp. 1-6, 2021. DOI: 10.1123/jsr.2020-0337.

[14] Suherman Ws, Dapan, Guntur, Muktiani Nr., "Development of traditional children play based instructional model to optimize development of kindergarteners' fundamental motor skill," Cakrawala Pendidikan, vol. 38, no. 2, pp. 356-365, 2019. DOI: 10.21831/cp.v38i2.25289.

[15] Horička P, Šimonek J, Paška L., "Relationship between reactive agility, cognitive abilities, and intelligence in adolescents," Journal of Physical Education and Sport, vol. 20, no. 3, pp. 2263-2268, 2020. DOI: 10.7752/jpes.2020.s3304. 